\title{
Establishing a Common Ground for the Use of Structural Equation Modelling for Construction Related Research Studies
}

\author{
Ayodeji Emmanuel Oke, (Federal university of Technology, Nigeria) \\ Deji Rufus Ogunsami, (Federal university of Technology, Nigeria) \\ Stephen Ogunlana, (Hariot Watt University, UK)
}

\begin{abstract}
The use of structural equation modelling (SEM) for research studies in construction related field has been on the increase over the years. The essence of this study is not to compare the level of usage of SEM with other modelling methods, neither is it to examine its extent of adoption in construction management - as this has been researched in previous works - but to arrive at a common ground for future construction related research works, based on the findings and recommendations from existing studies on the subject of SEM. Research materials within and outside the field of construction management were reviewed and it was discovered that SEM using AMOS (covariance approach) is the most appropriate method for construction research studies. This is not just because it is the most available of the software programs, but because of the numerous benefits and advantages highlighted from previous studies. The study also recommended appropriate sample size as well as cut-off value for various required goodnessof-fit tests of SEM model.
\end{abstract}

Keywords: Construction, Construction research, Goodness-of-fit measures, Software programs, Structural equation model, Structural equation modelling

\section{Introduction}

Previous studies in the field of construction have identified and used a number of methods for generating and testing of models and frameworks. Among these methods are Regression Equations of various types (e.g. linear, multiple, logistic, etc.), System Dynamic (SD), Artificial Neural Network (ANN), Structural Equation Modelling (SEM), etc. This paper is devoted to SEM.

\section{Advantages and Benefits of SEM}

The benefits of structural equation modelling (Bagozzi and Yi, 2012; Henseler, 2012; Ringle et al, 2012) include that it provides an integrative function, that is, a single umbrella of methods under leading programs. It helps researchers to be more precise in their specification of hypotheses and operationalizations of constructs; takes into account reliability of measures in tests of hypotheses in ways beyond the averaging of multi-measures of constructs; guides exploratory and confirmatory research in a manner combining self-insight and modelling skills with theory. It often suggests novel hypotheses originally not considered and opens up new avenues for research. It is useful in experimental or survey research, cross-sectional or longitudinal studies, measurement or hypothesis testing, within and across groups and institutional or cultural contexts; and is easy to use. Henseler (2012) identified the advantages of SEM to include its abilities to model latent variables, correct for measurement error, specify errors and their covariance structures and estimate entire theories simultaneously. It allows a researcher to model and predict relationships between construct variables in the hypothesised manner. 
Structural Equation Modelling is an advanced multivariate technique to examine multiple dependence relationships between variables simultaneously (Singh, 2009, Harris and Schaubroeck, 1990). SEM is generally preferred to other modelling methods due to the reasons highlighted by Bryne (2010); Roberts, et al (2010); Ringle, et al (2012); and Singh (2009). The reasons include: it takes a confirmatory rather than an exploratory approach to data analysis while most other methods including regression equations are descriptive, i.e. exploratory; it provides explicit estimates for measuring errors that traditional multivariate procedures are incapable of either assessing or correcting; the sample size can easily be regulated; it can be used for non-normal data; it allows for the use of formatively measured latent variables; data analysis using SEM incorporate both observed and unobserved variables unlike other methods incorporating only the observable variables; it tests a priori relationship rather than allowing the technique or data to define the nature of relationship between the variables; and it provides alternative methods for modelling multivariate relations. Yuan, et al (2010) concluded that SEM is an established method for social science research. This therefore establish the usefulness of SEM for construction related research works since it is social-science research inclined.

\section{Research Methodology}

A review of existing literature in the area of SEM was carried out with emphasis on differences in approaches, software programs, sample size, data and respondents' type as well as necessary tests required in the final selection of SEM model. However, the examined research materials were not limited to construction related areas only.

\section{Approaches to SEM}

There are three approaches for structural equation modelling as identified in the literature (Hensler, 2012; Hwang, et al 2010; Ringle, et al 2012; Yuan, et al 2010). The approaches indicated in table 1 depend on the adopted software programs and they are: covariance structure analysis (C-SEM); partial least square (PLS); and generalized structured component analysis (GSCA). Hwang et al (2010) referred to the first two methods as traditional approaches

\begin{tabular}{|c|c|c|c|}
\hline Factors & C-SEM & PLS-SEM & GSCA \\
\hline \multicolumn{4}{|l|}{ Model specification } \\
\hline Latent variable & Factors & Components & Components \\
\hline Number of equations & One & Two & One \\
\hline Model parameter & $\begin{array}{l}\text { Loadings. path coefficients, } \\
\text { error variances, factor } \\
\text { means and/or variance }\end{array}$ & $\begin{array}{l}\text { Loadings, path coefficients, } \\
\text { component weights }\end{array}$ & $\begin{array}{l}\text { Loadings, path } \\
\text { coefficients, } \\
\text { component weights }\end{array}$ \\
\hline \multicolumn{4}{|l|}{ Parameter specification } \\
\hline Input data & Covariances/correlations & Individual-level raw data & $\begin{array}{l}\text { Individual-level raw } \\
\text { data }\end{array}$ \\
\hline Estimation method & $\begin{array}{l}\text { Maximum likelihood } \\
\text { (mainly) }\end{array}$ & Least squares & Least squares \\
\hline Global optimization function & Yes & No & Yes \\
\hline Normality assumption & $\begin{array}{l}\text { Required for maximum } \\
\text { likelihood }\end{array}$ & Not required & Not required \\
\hline Model fit measures & Overall and local & Local & Overall and local \\
\hline
\end{tabular}

Oke A E et al. (2012) 'Establishing a common ground for the use of structural equation modelling for construction related research studies', Australasian Journal of Construction Economics and Building, 12 (3) 89-94 
while the third is known as alternative method. C-SEM involves the use of such software programs as LISREL, AMOS, EQS and MPlus while PLS can be implemented using LVPLS, PLS-Graph, Smart-PLS and VisualPLS. GSCA analysis is only implemented by the use of GeSCA software program.

Covariance Structural Equation Modelling (C-SEM) using Analysis of Moment Structure (AMOS) software is recommended for construction related research works. Hwang, et al (2010) while comparing the three approaches, concluded that C-SEM has been found to recover loadings, parameters and path coefficients better than the others and it also produces unbiased parameter estimates. Moreover, Hensler (2012) in comparing C-SEM with GSCA observed that GSCA substantially over-estimates direct effect in mediation analysis, partially invalid and provide inconsistent estimates. However, PLS-SEM should be considered as an alternative where C-SEM could not be used for any reason

\section{Sample Size}

The role of sample size is crucial in all statistical analysis (Lucko and Rojas, 2010). The more sophisticated the statistical analysis the larger the sample needed. Therefore, the sample size requirement in this study is a function of the model or framework development method in consideration.

SEM, like other statistical techniques, requires an appropriate sample size in order to produce reliable estimates (Hair, Anderson, Tatham and Black 2008). Gorsuch (1983) suggested at least 5 participants per construct and not less than 100 individuals per data analysis. Harris and Schaubroeck (1990) proposed a sample size of 200 at least to guarantee robust structural equation modelling. Kline (2010) suggested that a very complicated path model needs a sample size of 200 or larger while Bagozzi and Yi (2012) proposed that the sample size should be above 100, preferably above 200. In addition, Yuan, et al (2010) after evaluating different models based on various numbers of respondents opined that a sample size of between 300 and 400 should be appropriate for structural equation models using ordinal data. This is supported by Hair, et al (2008) who recommends a sample size of at least 200 but not exceeding 400. It was further pointed out that when the sample size exceeds 400 to 500 participants, the SEM analysis becomes too sensitive and almost any difference is detected, making goodness-of-fit measure show poor fit. It can thus be concluded that a minimum and maximum sample of 200 and 400 respectively, is needed for SEM research studies.

\section{Analysis and Selection of Best-fit model}

Like any other model, it is not always practicable and appropriate to accept the first result of analysis of a model. There is always a need to subject the model to various tests with the sole purpose of validating the model and arriving at the best-fit model. In SEM, two stages i.e. model selection and evaluation are identified. Model selection involves testing the factors and testing the model. In testing the factors, exiting studies opin a need to carry out factor analysis on latent variables and Yuan, et al (2010) suggested a cut-off value of 0.50 while Chinda and Mohamed (2008) used 0.45 in modelling construction safety culture. The essence of the test according to Barrett (2007) is to ensure the elimination of attributes with low correlations with the attributes of other latent factors in the final SEM. The cut-off value is affected by sample size but a range of 0.45 to 0.50 is deemed appropriate.

The second stage of model selection involves using selection criteria to declare one model superior and treating it as a best working hypothesis until a better model is proposed (Preacher and Merkle, 2012). Molenaar et al (2000) opined that a feasible model should be selected based

Oke A E et al. (2012) ' Establishing a common ground for the use of structural equation modelling for construction related research studies', Australasian Journal of Construction Economics and Building, 12 (3) 89-94 
on the recommended Goodness-of-fit (GOF) measures and the model that satisfies both theoretical expectations and GOF should be finally selected for SEM analysis. Standard indices of model fits can be established by using t-tests and R-squares for model equation (Doloi, et al. 2011 ) as well as chi-square $\left(\chi^{2}\right)$ goodness-of-fit statistics (Bagozzi and Yi, 2012; Singh, 2009). The essence of these tests and the recommended level presented in table 2 according to Preacher and Merkle (2012), is to formulate a useful approximation model that fits well; has easily interpretable parameters; approximates reality in as parsimonious a fashion as possible; and can be used as a basis for inferences and predictions. However, Bagozzi and Yi (2012) opined that research can rely on five of the identified fit indices, that is, $\chi^{2}$, RMSEA, nonnormed fit index (NNFI/TLI), CFI and SRMR. Table 2 indicate the recommended cut-off values of various fit indices based on the recommendations of various research works. However, there is no need for rigidity as this is easily affected by other factors such as sample size, type of data, number of variables, etc.

In order to evaluate the appropriateness of the measurement model used for final SEM, Jin, Doloi and Gao (2007) suggested that the strength of the measurement model should be established by performing the Cronbach's reliability test. However, there are no discrepancies as both Doloi, et al. (2011) and Bryne (2010) suggested a cut-off value of 0.7 as an acceptable level of initial consistency. The closer the value is to 1 , the more reliable the model will be.

\begin{tabular}{|c|c|c|c|c|c|}
\hline Fit indices & Doloi et al (2010) & $\begin{array}{l}\text { Bagozzi } \\
\text { and } \mathrm{Yi} \\
(2012)\end{array}$ & Singh (2009) & $\begin{array}{c}\text { Chinda \& } \\
\text { Mohamed } \\
(2008)\end{array}$ & $\begin{array}{l}\text { Recommended } \\
\text { value(s) }\end{array}$ \\
\hline$x^{2} /$ Degree of freedom & 1 to 2 & 0 to 2 & 1.00 to 2.00 & $<2.00$ & 1.00 to 2.00 \\
\hline Goodness of fit (GFI) & 0 (no fit) - 1 (perfect fit) & 0 to $\geq 1$ & 0.00 to 1.00 & & 0.00 to 1.00 \\
\hline $\begin{array}{l}\text { Root mean square error of } \\
\text { approximation (RMSEA) }\end{array}$ & $\begin{array}{l}<0.05 \text { (very good) - } \\
0.1 \text { (threshold) }\end{array}$ & $\leq 0.07$ & $\leq 0.05$ to $\leq 0.08$ & $\leq 0.10$ & $<0.05$ to 0.07 \\
\hline $\begin{array}{l}\text { Standardized root mean } \\
\text { square residual (SRMR) }\end{array}$ & & $\leq 0.07$ & & & $<0.05$ to 0.07 \\
\hline Comparative fit index (CFI) & 0 (no fit) - 1 (perfect fit) & $\geq 0.93$ & 0 to 1 & $>0.90$ & 0.93 to 1.00 \\
\hline Tucker-Lewis index (TLI) & 0 (no fit) -1 (perfect fit) & $\geq 0.92$ & $\geq 0.95$ & - & 0.95 to 1.00 \\
\hline Normed fit index (NFI) & 0 (no fit) - 1 (perfect fit) & & 0.60 to 0.90 & - & 0.60 to 1.00 \\
\hline Incremental fit index (IFI) & 0 (no fit) - 1 (perfect fit) & & 0 to 1 & $>0.90$ & 0.93 to 1.00 \\
\hline Relative fit index (RFI) & 0 (no fit) - 1 (perfect fit) & & & - & 0.90 to 1.00 \\
\hline
\end{tabular}

Table 2 Recommended level of Goodness-of-fit (GOF) measure

\section{Conclusion and Recommendation}

Having established the benefits, usefulness and advantages of using SEM for construction related research studies, it could be concluded from previous research findings that the usefulness of SEM in the field of construction is clearly established. The field is social-science related and the majority of the data are ordinal - mostly from the perceptions and opinions of construction professionals - and these are major areas of strength of SEM. More so, Covariance Structural Equation Modelling (C-SEM) using Analysis of Moment Structure (AMOS) software is recommended due to its advantages over other identified methods. The sample size for

Oke A E et al. (2012) ' Establishing a common ground for the use of structural equation modelling for construction related research studies', Australasian Journal of Construction Economics and Building, 12 (3) 89-94 
developing SEM should be within the range of 200 and 400 while cut-off values for various tests of goodness-fit were also recommended.

\section{References}

Bagozzi, R. P.\& Yi, Y. (2012) 'Specification, evaluation, and interpretation of structural equation models', Journal of the Academy of Marketing Science, 40, 8-34

Barrett, P. (2007) 'Structural Equation modelling: adjudging model fit', Personality and Individual Differences, 42, 815-824

Bryne, B. M. (2010) Structural Equation Modelling with AMOS: Basic Concepts, Applications and Programming, (2nd ed.), Routledge, Taylor and Francis Group, New York.

Chinda, T. \& Mohamed, S. (2008) 'Structural equation model of construction safety culture', Engineering, Construction and Architectural Management, 15 (2), 114-131

Doloi, H, lyer, K. C. \& Sawhney, A. (2010) 'Structural equation model for assessing impacts of contractor's performance on project success', International Journal of Project Management, 29, 687-695

Gorsuch, R. L. (1983) Factor Analysis, Lawrence Erlbaum, Hillsdale, New Jersey

Hair, J.F., Anderson, R.E., Tatham, R.L., \& Black, W.C. (2008) Multivariate Data Analysis, (7th ed.). Prentice Hall Publisher, Upper Saddle River, New Jersey

Harris, M. \& Schaubroeck, J. (1990) 'Confirmatory modelling in organizational behaviour/human resource management: issues and applications', Journal of Management, 16 (2), 337-360

Henseler, J. (2011) 'Why generalized structured component analysis is not universally preferable to structural equation modelling', Journal of the Academy of Marketing Science, 40, 402-413

Hwang, H., Malhotra, N. K., Kim, Y., Tomiuk, M. A., \& Hong, S. (2010) 'A comparative study on parameter recovery of three approaches to structural equation modelling', American Marketing association, 48 (August), 699-712

Jin, X.H., Doloi, H. \& Gao, S.Y. (2007) 'Relationship-based determinants of building project performance in China', Construction Management and Economics , 25, 297-304

Kline, R. B. (2010) Principles and Practice of Structural Equation Modelling. (3rd ed.), The Guilford Press, New York

Lucko, G. \& Rojas, E. M. (2010) 'Research validation: challenges and opportunities in the construction domain', Journal of Construction Engineering and Management, 136 (1), 127-135

Molenaar, K, Washington, S. \& Diekmann, J. (2000) 'Structural equation model of construction contract dispute potential', Journal of Engineering and Management, 126 (4), 268-277

Preacher, K. J. \& Merkle, E. C. (2012) 'The problem of model selection uncertainty in structural equation modelling', Psychological Methods, 17 (1), 1-14

Ringle, C. M., Sarstedt, M., \& Straub, D. W. (2012) 'A critical look at the use of PLS-SEM in MIS Quarterly', MIS Quarterly, 36 (1), 3-16

Roberts, N, Thatcher, J. B. \& Grover, V. (2010) 'Advancing operations management theory using exploratory structural equation modelling techniques', International Journal of Production Research, 48 (15), 4329-4353

Oke A E et al. (2012) ' Establishing a common ground for the use of structural equation modelling for construction related research studies', Australasian Journal of Construction Economics and Building, 12 (3) 89-94 
Singh, R. (2009) 'Does my structural model represent the real phenomenon?: a review of the appropriate use of structural equation modelling (SEM) model fit indices', The Marketing Review, 9 (3), 199-212

Yuan, K.., Wu, R., \& Bentler, P. M. (2010) 'Ridge structural equation modelling with correlation matrices for ordinal and continuous data', British Journal of Mathematical and Statistical Psychology, 64, 107-133 